\title{
Implementation of Reliability Centered Maintenance Method for the Main Engine of Tugboat X to Select the Maintenance Task and Schedule
}

\author{
Dwi Priyanta $^{1}$, Nurhadi Siswantoro ${ }^{2}$, Madina Nur Pratiwi ${ }^{3}$ \\ (Received: 01 August 2019 / Revised: 18 June 2020 / Accepted: 29 June 2020)
}

\begin{abstract}
A tugboat used for maneuvering, primarily pulling or pushing bigger vessel in open seas or river to be able to lean in port. PT.X known as a company has a prominent business field in provides such as tugboat. On the PT.X Annual Report of 2018 reported several cases that caused that related to the reliability of the main engine. The failure occurred on the main engine, affected commission days targeted was not achieved. Reliability-Centered Maintenance (RCM) is a maintenance method that focused on elevating the reliability of a component in the system(s). RCM used a risk management principle to determine the maintenance task and schedule appropriately. RCM process implemented using the Guide for Survey Based on Reliability-Centered Maintenance (RCM) by the American Burau of Shipping (ABS). Based on the results of this research, there were 38 task list type which is obtained based on the analysis of maintenance task allocation and planning. The percentage of maintenance types from each failure mode (task type) Preventive Maintenance (PM) is 29\%, Condition Monitoring (CM) is 29\%, Finding Failure (FF) is $\mathbf{2 1 \%}$ and One-Time Change (OTC) is $\mathbf{2 1 \%}$. Work package for each interval is created from every failure mode for each interval for maintenance/inspection.
\end{abstract}

Keywords-FMECA, main engine, maintenance schedule, RCM, tugboat,

\section{INTRODUCTION}

$\mathrm{I}$ ndonesia is one of the largest archipelagoes in the world because it exceeds 17,000 islands. The sea is very identical to the resources in it. Several sectors can be developed, such as aquaculture, marine tourism, sea transportation, mineral resources, coastal forests, nonconventional resources, small islands, aquatic product processing industries, and others. The government try to balancing the supply and demand for goods and services, from one region to another. With the encouragement from the government, driving growth in sea transportation.

The increasing sea transportation sector, there are needs supporting system for helping the development industry, such as tugboat use. Tugboat has a function in port operations to attract and encourage ships to be able to berth to carry out loading/unloading activities. Tugboats also have a role in the industry, such as the use of barges that require tugboats [1].

Tug and Barge is sea transportation that can carry large amounts of cargo with a size of $300-350 \mathrm{ft}$. A barge is capable of carrying 7000 tons of bulk cargo. This kind of economic value of the tugboats more efficient compared to other types of ships. Because of

\footnotetext{
Dwi Priyanta, Department of Marine Engineering, Institut Teknologi Sepuluh Nopember, Surabaya 60111, Indonesia, Email: priyanta@its.ac.id

Nurhadi Siswantoro, Department of Marine Engineering, Institut Teknologi Sepuluh Nopember, Surabaya 60111, Indonesia, Email: nurhadi@ne.its.ac.id

Madina Nur Pratiwi, Hochschule Wismar, Germany, Email Madinapratiwi23@gmail.com
}

this, tug and barge dominate Indonesia's shipping lanes, especially coal, sand, iron ore, and other bulk loads [2].

The shipping industry is known to have high potential or risks related to safety. If an accident occurs, it will cause various consequences related to human safety, financial and environmental. Ship accidents consist of collisions, equipment failures, explosions, fires, leaks, aground, overturned, sinking, and others [2].

Quoted from the P\&I club (Protection and Indemnity insurance) in analyzing statistical data found human error factor is a common factor that caused machine operation failures Human error defined as incorrect operation of the machine or maintenance/inspection of the engine.

The statistical data analyzed by the P\&I club from the total number of 2,000-2,500 accidents annually. The number of each cause of accidents such as maneuvering accidents (red), engine damage (blue), and other accidents (green). This data shows that the percentage of accidents due to engine damage e reaches $15 \%$ of the total number of ship accidents per year. Other accidents defined due to hull \& structure, irresistible force, mishandling of combustible materials, and mismanagement of storage areas, and others, see Fig. 12 [3].

Based on ship accident data with engine problems due to maintenance, which can cause the ship to fail to operate. Ship failure will adversely affect companies that own ship charter. Because it has a low-performance ship or in other words does not have enough availability needed by the user. 


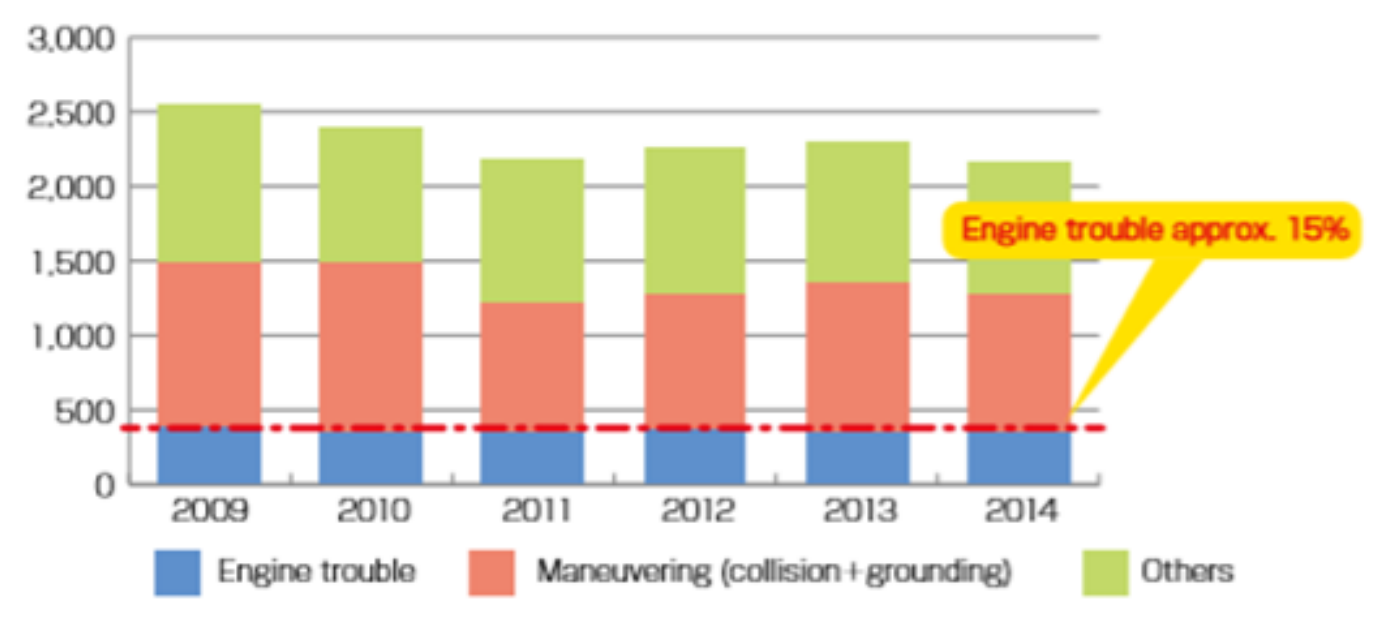

Figure. 1. Trend of number of ship accidents (2009-2014) [3].

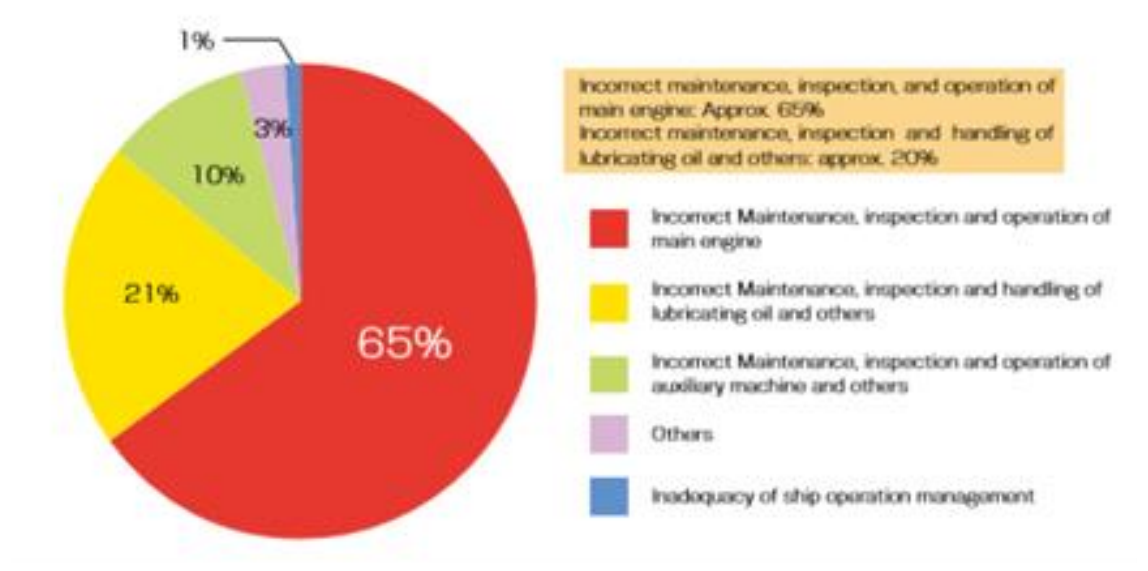

Figure. 2. Trend of number of ship accidents (2009-2014) [3].

If a ship accident occurs, it can decrease the operational day of a vessel. Then, the targeted commission days that have been agreed by the second party has not reached. When this happens, both parties will incur the losses. The users of the charter ship will face loss costs because business mobility hampered, and the shipowner will get a penalty from the user because the ship used does not reach the commission days that targeted. Also, charter vessel owners will lose the trust of the user because they cannot guarantee the quality of the charter ship [10].

Therefore, to ensure that the tugboat is operating in an optimal condition with implementing appropriate management maintenance. Because efficient management maintenance will turn into optimal system performance, it also maintains the life-time of each component on a system.

\section{METHOD}

A. Case Study

PT. $\mathrm{X}$ is a state-owned company which has a business sector engaged in shipping. PT. X has 12 operating locations throughout Indonesia, and those are Medan, Makassar, Jambi, Dumai, Cilacap, Balikpapan, Plaju, Batam, Tanjung Priok, Surabaya, Bontang, and Sorong.
PT. X offers several products and services, namely provider of ships as operational fleets, charters \& brokerage, ship agency services, vessel management, port management, shipping fuel for ships or tankers, and others. PT. X ships have various types of vessels, such as tankers, AHTS (Anchor Handling Tug Supply vessel), tugboats, LNG (Liquefied Natural Gas vessels), mooring boats, SPOB (Self Propelled Oil Barge), RIB (Rigid Inflatable Boat), and others [4].

\section{B. Reliability Centered Maintenance II}

RCM itself is a qualitative method for determining applicable preventive maintenance tasks and is an effective way to maintain the main functions of selected components or systems. RCM focuses on maintenance only on items that affect the reliability of the system, thus making the maintenance program costs effective in the long run. Because the results of RCM based on the context of the operation [5]. RCM consists of a mixture of reactive maintenance practices, such as time-based, condition-based, and proactive maintenance. This maintenance strategy is applied integrally with other maintenance strategies to take advantage of the strength of each strategy to maximize the reliability of facilities and equipment while minimizing life-cycle cost. 
RCM also manages available human and financial resources according to the importance of the equipment, that is, according to the loss or risk that can be caused by its failure. Therefore, this strategy is used to improve efficiency by increasing equipment reliability.

$\mathrm{RCM}$ can also interpret as a process used to determine what must be done to ensure that each physical asset operates appropriately following its design and function. RCM answers seven main questions to the system under study. The seven questions are as follows:

1. What are the functions and associated performance standards of the asset in its present operating context (system function)?

Explanation: Before it is possible to implement RCM, a function definition determines for each asset and operational standards that must achieve. The process of using it in the context of operations can be carried out by determining what wants to be needed and ensuring that assets can meet the needs. What is expected by the asset user can divide into two categories, namely:

- The main functions, including issues such as speed, results, capacity, product quality, and services.

- Secondary functions, assets are expected to do more than fulfil their primary function. Can be expected to have functions in the fields of safety, control, comfort, structural integrity, economy, protection, operational efficiency, and others.

2. In what ways does it fail to fulfil its functions (functional failure)?

Explanation: Functional failure is a component failure to meet the expected system function. Functional failure achieved by adopting an appropriate approach to failure management. In the RCM process, there are two levels carried out, namely:

- Identifying conditions that considered as fail conditions.
- Ask about events that can cause assets to fail.

3. What cause each functional failure (failure modes)? Explanation: In the previous stage, functional failure identified. Next is to try to identify the possibility of failure. The causes of failures in components that have failed and do not meet operational standards are called failure mode.

4. What happens when each failure occurs (failure effect)?

Explanation: Failure of the component will have an impact on work operations. This fourth step is an illustration that will occur when a failure mode occurs. This description must include all the information needed to support an evaluation of the consequences of failure.

5. In what way does each failure matter (failure consequences)?

Explanation: Failure that occurs in an asset will have consequences. Therefore, asset users will try to avoid these failures. If the failure does not have a significant effect, usually the user will decide not to do routine maintenance. The high strength of RCM is to recognize that the consequences of failure are far more important than their technical characteristics. The RCM process classifies these consequences into four groups, shown in Fig. 3.

6. What can be done to predict or prevent each failure (proactive task)?

Explanation: the proactive task is a task that is carried out before a failure occurs, to prevent items from entering a state of failure. Proactive tasks perform traditionally or predictive and preventive. RCM uses the term Scheduled Restoration.

7. What should be done if a suitable proactive task cannot be found (default action)?

Explanation: A default action is a state of failure and chooses when it is not possible to identify a practical, proactive task. Default actions include failure-finding, re-design, and run-to-failure [6].

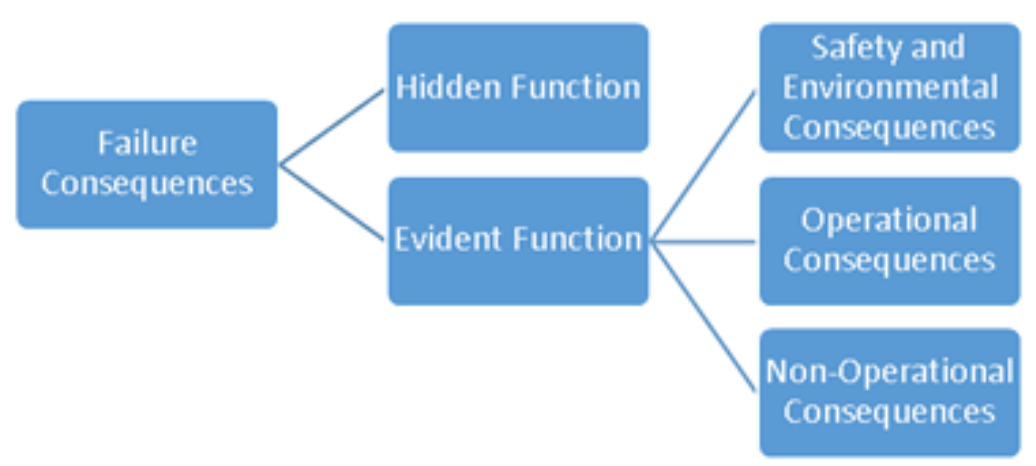

Figure. 3. Categories of failure consequences. 


\section{Failure Mode, Effects, and Criticality Analysis (FMECA)}

The FMECA methodology designed to assess the risks associated with all failure modes. The aim of FMECA is to design maintenance procedures needed to eliminate the point of failure as well as the catastrophic or critical consequences of the failure. The main goal is to initiate actions that reduce the chance of failure in the process. FMECA also increases knowledge about the system and help to increase the cost effectiveness of preventive maintenance programs.

\section{Steps of ABS Rules}

The ABS or American Bureau of Shipping announced requirements for the Reliability-centered Maintenance (RCM) program in order to enhance reliability for vessels' machinery systems.According to [7], to provide a process to optimize maintenance tasks and achieve optimal reliability will be used risk assessment techniques and RCM analysis. The ABS has reviewed the RCM analysis area and modified the method for marine applications. Available procedures and compliance with recognized standards are SAE JA1011, SAEJA1012, IMO Annex 3 and Annex 4 for implementing the Reliability-centered Maintenance (RCM) process [8]. This is the following step of implementing RCM by ABS rules:

1. System Modeling, Functions and Functional Failures

The first step will require an analysis of the operation mode of the ship and the functional system of the main engine. The system will be modelled as a hierarchy for FMECA purposes, at the next step. ABS has ordered in hierarchical, as in Fig. 4. A component defined as the lowest level of the functional hierarchy that can identify the functions of the group, failure mode, and physical units that can be considered preventive maintenance planning. The system block diagram will visualize the structural hierarchy and identified each functional system. Then the various functional failures would be identified. ABS also have a template for diverse system subject to ABS rules and special periodical survey of machinery requirements on ships.

2. Conduct Failure Modes, Effects, and Criticality Analysis (FMECA)

The next step is to show the consequences caused by the failure mode. In ABS Guidance also has the classification of effect failure. Table 1 shows the severity level, from nothingness of effect, two progressive functional degradations to whole loss of function. From the approaches, the certification process would be easier to determine the effect of failure on functional groups when a component has a failure. Probability of other elements of risk is the frequency of failure mode.

To prevent failure happens, collecting data of functional failure is the answer. Next step is the preparation of the risk matrix. The risk matrix is a risk level table organized based on the combination of consequence level and frequency of failure. The standard is used to determine the risk matrix is derived from ABS Guidance in Table 2.

If all step of analysis of failure mode, effects, and criticality analysis has been completed. So, the result of the analysis needs to be filled into the worksheet. ABS standard requires the application of a bottom up FMECA.

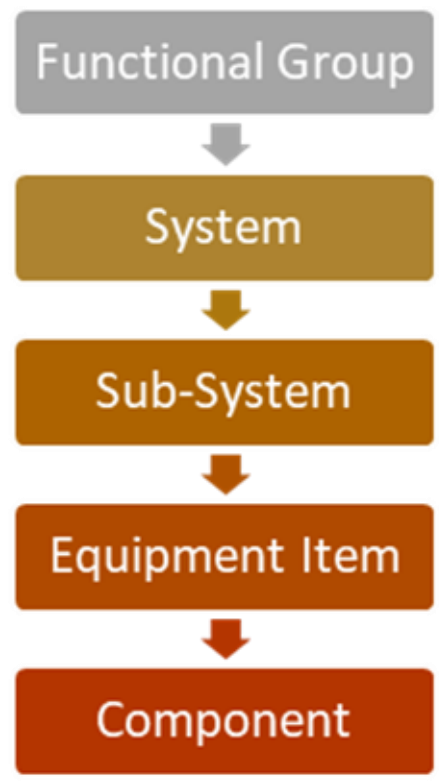

Figure. 4. Functional hierarchy. 
TABLE 1.

\begin{tabular}{cll}
$\begin{array}{c}\text { Severity } \\
\text { Level }\end{array}$ & $\begin{array}{c}\text { EXAMPLE OF CONSEQUENCES/SEVERITY LEVEL DEFINITION [9] } \\
\text { Description for } \\
\text { Severity Level }\end{array}$ & \multicolumn{1}{c}{ Definition for Severity Level } \\
\hline 1 & Minor, Negligible & $\begin{array}{l}\text { Functions are not affected, no } \\
\text { significant operational delays, } \\
\text { interference }\end{array}$ \\
2 & Major, Marginal, & $\begin{array}{l}\text { Functions are not affected, but failure } \\
\text { detection/repair actions do not work. } \\
\text { Or reduced functionality resulted in } \\
\text { operational delays. } \\
\text { Reduced functionality, or faulty } \\
\text { machining, significant operational } \\
\text { days. } \\
\text { Full function loss }\end{array}$ \\
& Critical, Hazardous, \\
& Significant & Catastrophic, Critical
\end{tabular}

TABLE 2.

EXAMPLE OF RISK MATRIX [9]

\begin{tabular}{cccccc}
\hline \multirow{2}{*}{$\begin{array}{c}\text { Severity } \\
\text { Level }\end{array}$} & \multicolumn{5}{c}{ LXKAMElihood of Failure } \\
\cline { 2 - 6 } & Improbable & Remote & Occasional & Probable & Frequent \\
\hline 4 & Medium & Medium & High & High & High \\
3 & Low & Medium & Medium & High & High \\
2 & Low & Low & Medium & Medium & High \\
1 & Low & Low & Low & Medium & Medium \\
\hline
\end{tabular}

\section{E. Maintenance Task Allocation and Planning}

Maintenance task allocation and planning is the deliverable of this thesis. There are maintenance task categories for selecting the maintenance tasks and maintenance task interval to determine the interval of maintenance.

\section{Maintenance Task Categories}

Maintenance task allocation and planning generated from the RCM analysis are divided into several categories based on location and parties required to carry out maintenance activities, including:

- Category A, maintenance activities can be carried out directly by the crew even when the ship is in operational (sailing).

- Category B, if a component has been in the maintenance schedule or has a failure, the shipowner is required to perform maintenance and repair of the ship in a non-operational condition. The maintenance may need shipyard equipped with facilities for ship repair. The owner is also required to be accompanied by the vendor during maintenance activities to ensure that existing maintenance activities are under existing standards on the components themselves.

○ Category $\mathrm{C}$, maintenance activities on the components must be carried out when the ship is not operating. Maintenance must be carried out using repair and maintenance facilities at the dry dock.
2. Maintenance Task Interval

Maintenance Task Interval is the period-time of maintenance performed on each component. Task intervals derived from RCM analysis do not need to be following the existing maintenance schedule (calendar-based maintenance schedule) [14-15]. This needs to be integrated with the existing maintenance schedule because the task interval can be done either shorter or longer than the existing schedule depending on several criteria as follows:

○ Maintenance activities with high safety and environmental consequences, if the failure occurs, the maintenance interval should be shorter than the existing maintenance schedule to ensure that the possible failure of the components will not dangerous during work operations.

o If maintenance activities with the consequences of disruption of work operations when a failure occurs, then the maintenance interval can be shorter or longer than the existing maintenance schedule. However, when make a decision the maintenance interval schedule is longer than the existing schedule, this must get the approval of the party responsible for maintenance in the company. In analyzing the maintenance task and time interval, it needed to fill into a maintenance worksheet. If all the steps in the maintenance task allocation and planning analysis have been completed, then it is necessary to conclude from the results of the analysis. 


\section{RESULT AND DISCUSSION}

\section{A. Data Collection}

After doing the literature study, selecting a system and collecting data performed. The data retrieval process at PT. $\mathrm{X}$ is conducting in three ways, namely Observation in Company, Interview, and physical Data on the company. The data are explained down below.

1. Observation in Company

- Maintenance System, How the company prevent the break downtime with PMS (Planned Maintenance System)

2. Interview

- Maintenance Activity, How the company maintain the communication between the crew onboard and the superintendent

3. Data from the Company

- Main Engine Specification, to know about the specification of each part that included into the main engine.

- Operational Data, To know about the operational history of the main engine

- Data Failure \& Repair (Log Book), To see frequently failure and repair history to each equipment .

4. PID \& PFD, To see the flow diagram of the system is consist of the main engine

\section{B. Research Object}

This study examined the X tugboat owned by PT. X. After screening the data in the company, the Basic main engine was selected. The data of tugboat owned by PT. $\mathrm{X}$ explains at table 3 [11].

\section{System Block Diagram and Functions}

FBD is used to describe the relationship between one function and another function in the system. In addition to showing the functions and parts in them, the FBD also explained the relationship and workflow between functions that make up the system and the settings that require the system. As a minimum the block diagram is to contain:

- Partitions of functional groups into the system, equipment items and components

- All inputs and outputs are labeled as appropriate and the identification numbers that each system referenced consistently

- All redundancy, alternative signal paths and other engineering features provide a "fail-safe" action.

D. Failure Mode, Effect and Criticality Analysis (FMECA)

This stage is how implementing RCM by ABS rules step by step. Failure Mode, Effect and Critical Analysis (FMECA) utilizing with RCM method of ABS Rules.
The following steps in implementing FMECA in this research are as follows.

1) Identification of Failure Modes

Failure Mode is how the failure is observed. This generally explains how failures occur and their impact on equipment or systems. All equipment items or components related to the cause of the identified failure mode must be identified

2) Failure Effect

- The effects of the failure for each failure mode are to be listed as follows:

- The Local Effect is to describe the initial change in the equipment item or component operation when the failure mode occurs.

- The Functional Failure is to describe the effect of the failure mode on the system or functional group

- The End Effect is to describe the overall effect on the vessel addressing propulsion, directional control, environment, fire and/or explosion. One failure mode may result in multiple end effects.

3) Failure Detection

Failure detection means, such as visual or sound warning devices, automatic sensing devices, sensor instrumentation, or other unique indications, if applicable. The term "clear" should be demonstrated. Where detection failure is unclear, the term "hidden" should be demonstrated.

4) Corrective Measures

The provisions are the features of the design at each level to negate the effects of the failure mode. Provisions requiring operator action to circumvent or mitigate the effects of failure mode must be provided.

5) Criticality Analysis

Current Likelihood is explained in five categories in determining the level of frequency of damage (failure mode). The five categories are improbable, remote, occasional, probable, and frequent. The risk level of each component is analysed using FMECA from $\mathrm{ABS}$ rules that obtained from a combination of the severity and likelihood descriptors in the risk matrix. The analysis must be filled into bottom-up FMECA Worksheet to decide the maintenance task of the main engine of Tugboat. To fulfil the RCM decision worksheet, it needs to answer the RCM decision diagram, which consists of failure consequences and the maintenance task techniques. Critique analysis is done simultaneously as part of the system design process. The analysis of criticism began as an integral part of the initial design process and was updated as a developing design. The critique analysis generates a relative size of the significance of the effect failure mode has on successful operations and system security [9][1213]. 
TABLE 3 .

TUGBOAT INFORMATION

\begin{tabular}{lc}
\hline & General information of Tugboat \\
\hline Year Built & 1996 \\
Type of Ship & Tugboat \\
Flag & Indonesia \\
LBP (m) & 31,52 \\
B (m) & 10,6 \\
H (m) & 4,96 \\
T (m) & 4,15 \\
GT & 413 \\
NT & 124 \\
DWT (ton) & 422 \\
Service speed & 12 \\
\hline & Main Engine Specification \\
\hline Type of propulsion & Reversible \\
Number of strokes & 4 \\
Number of cylinder & 9 \\
Power & $2100 \mathrm{~kW}$ \\
RPM & 1000 \\
\hline
\end{tabular}

\section{E. Maintenance Task and Schedule}

The result of this research is determines the maintenance task. The maintenance task and schedule based on the results of the analysis from the previous FMECA result.

Fig. 5 shows the distribution of the severity level analysis conducted on the main engine of the tugboat X. There are $31 \%$ (7 items) minor severity level, $17 \%$ (4 items) major severity level, 30\% (7 items) critical severity level, and $22 \%$ (5 items) catastrophic severity Level.
Fig. 6 shows the distribution of the maintenance category of FMECA analysis conducted on the main engine of the tugboat $\mathrm{X}$. There are 47\% (18 task type) of Category A, 45\% (17 task type) of Category B and 8\% (3 task type) of Category C. Each task type is decided based on logic tree analysis in the ABS Guidance.

Fig. 7 shows the recapitulation of task type on the whole maintenance category. There are 29\% (11 task type) of Preventive Maintenance (PM), 29\% (11 task type) Condition Monitoring (CM), 21\% (8 task type) of One-time Change (OTC), 21\% (8 task type) of Failure Finding (FF).

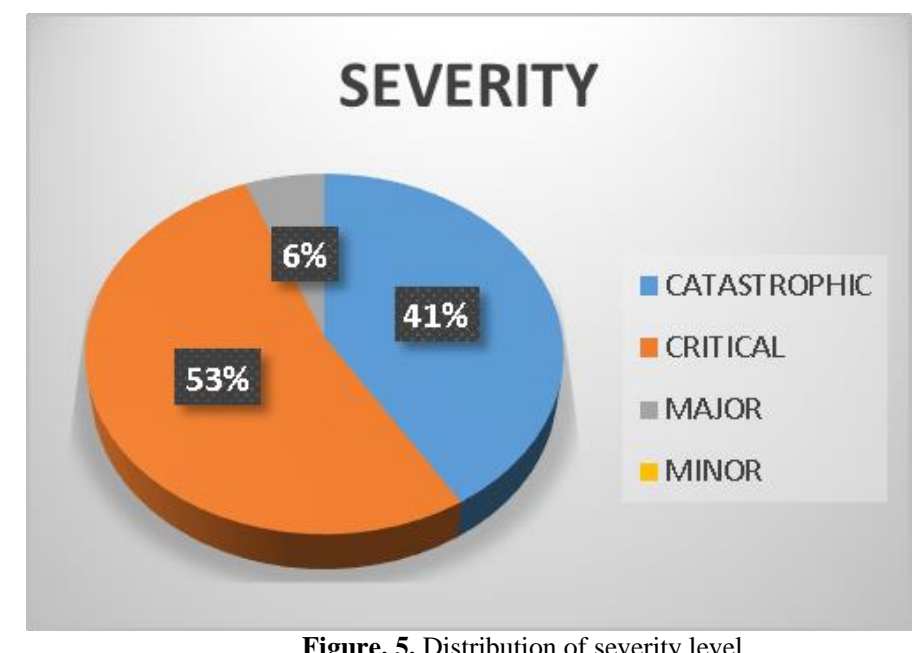

Figure. 5. Distribution of severity level. 


\section{MAINTENANCE CATEGORY}

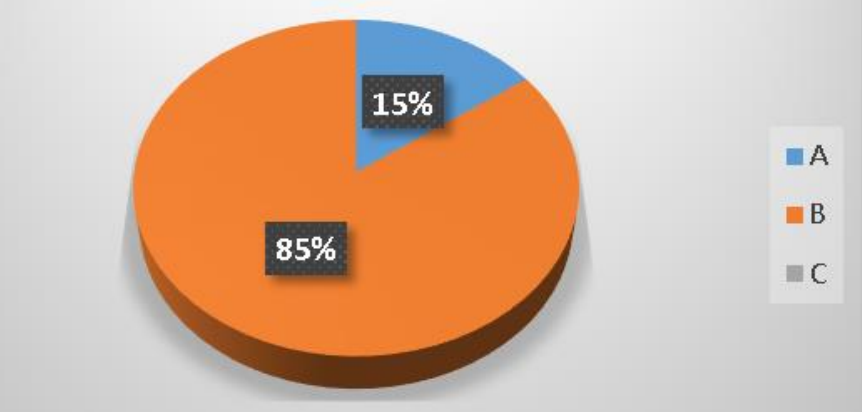

Figure. 6. Distribution of maintenance category

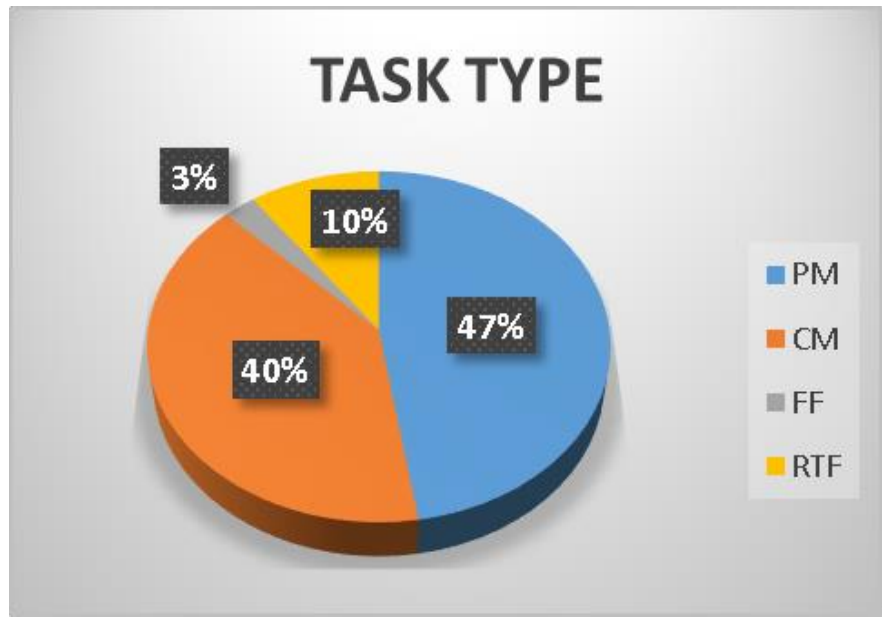

Figure. 7. Task type of maintenance task.

\section{CONCLUSION}

The Reliability-Centered Maintenance (RCM) method is using to determining the causes and the exact type of action of each failure mode. Historical repair list in 2018 and OREDA become the primary data in this analysis.

Based on the maintenance task allocation and planning analysis, the following results are obtained:

1. There are three maintenance task categories, which the main engine of tugboat $\mathrm{X}$ has 6 task list in category A, 34 task list in category B, 0 task list in category $\mathrm{C}$.

2. In all three categories, there are 40 task lists acquired. Which the type of treatment presentation of failure mode is $47 \%$ (19 task) of Preventive Maintenance (PM), 40\% (16 task) of Condition Monitoring (CM), $10 \%$ (10 task) of Run-toFailure (RTF) and 3\% (2 task) of Failure Finding (FF). Preventive Maintenance and Condition Monitoring maintenance are the main recommendations for this analysis to get the maximum operational time.

3. Based on the analysis, the projected risk of the main engine tugboat $\mathrm{X}$ has lower risk than before. Before the analysis, It has $88 \%$ Medium Risk and $12 \%$ High Risk. After the analysis, It has $50 \%$ Medium Risk and 50\% Low Risk.

\section{REFERENCES}

[1] T. Mori, "The Present Situation and The issues on tugboat business in Japan," Univerity Marketing and Distribution Sciences, p. 1, 2016.

[2] S. I. Sri, M. and A, "Mapping of Vessel Accident Characteristics in Indonesia Based on Investigation of KNKT," p. 2, 2017.

[3] P\&IClub, "P\&I Loss Prevention Bulletin, Thinking Prevention of Engine Trouble," P\&IClub, 2017.

[4] P. P. T. Kontinenta, "Annual Report 2018," PT. Pertamina Trans Kontinental, Jakarta, 2018.

[5] Z. M. Marcin K., "Reliability Centred Maintenance (RCM) Basics of Implementation and general characteristics," Journal of Machine Construction and Maintenance, p. 101, 2017.

[6] J. Moubray, Reliability-centred maintenance, 2nd ed., Industrian Press, 1997.

[7] R. M. Conachey, "Development of RCM Requiremnets for the Marine Industry," ABS Technicals Paper, pp. 69-80, 2004.

[8] R. M. Conachey and A., "Development of RCM Requirements for the Marine Industry," ABS Technical Papers, 2004.

[9] A. B. Shipping, Guide for survey based on machinery reliability and maintenance technical, Houston: American Bureau of Shipping, 2016.

[10] D. Perhubungan, "Statistik Perhubungan 2016 Buku II," Dinas Perhubungan Indonesia, Jakarta, 2016

[11] P. P. T. Kontinental, "Annual Report 2018," PT. Pertamina Trans Kontinental, Jakarta, 2018.

[12] J. Khan, "Applying Six Sigma to plant maintenance improvement programs," Proceedings MARCON 2006 - 3rd International Marketing Congress, Lahore, Pakistan, 2006. 
International Journal of Marine Engineering Innovation and Research, Vol. 5(2), Jun. 2020. 102-110 (pISSN: 2541-5972, eISSN: 2548-1479)

[13] M. A. Adale, "Evaluation of Maintenance Management Through Benchmarking in Geothermal Power Plants," United Nations University, Reykjavik, Iceland, 2009.

[14] G. and M. , "Identification of Critical Components using ANP for Implementation of Reliability Cantered Maintenance," 2018.

[15] D. and J. Raj, "CBM, TPM, RCM, and A-RCM - A Qualitative Comparison of Maintenance Management Strategies," p. 50, 2014. 